\title{
Maps highlight urban-rural differences in achieving Sustainable Development Goals
}

\section{Yunyu Tian}

Wageningen university \& Research

N. E. Tsendbazar

Wageningen University and Research Centre, Wageningen, Netherlands

\section{Eveline van Leeuwen}

Wageningen University https://orcid.org/0000-0002-3262-7030

Martin Herold ( $\nabla$ martin.herold@wur.nl)

Wageningen University https://orcid.org/0000-0003-0246-6886

\section{Article}

Keywords:

Posted Date: January 17th, 2022

DOI: https://doi.org/10.21203/rs.3.rs-1208399/v1

License: (c) (1) This work is licensed under a Creative Commons Attribution 4.0 International License. Read Full License 


\section{Sustainable Development Goals}

\section{Abstract}

Land use efficiency, energy efficiency, and air quality are key indicators when assessing urbanrelated Sustainable Development Goals (SDGs), yet recent trends and trade-offs in and around urban areas worldwide remain largely unknown. We use an Earth Observation approach to map the land-energy-air sustainability nexus and highlight distinct urban-rural gradients worldwide (2000-2015). In the Global South, urban areas perform relatively better in land-energy-air sustainability trends than rural areas, which are the least sustainable in our global comparative analysis. Comparatively, urban areas in the Global North tend to be less sustainable than their surrounding rural regions. Trade-offs among land-energy-air trends are mostly related to energy efficiency versus air quality in urban areas, while trade-offs between land use efficiency and the other two SDGs (energy-air) are more pronounced in rural areas. Integrating satellitedata is crucial for tracking the progress of the land-energy-air nexus and can guide contextspecific strategies to account for urban-rural differences in achieving sustainability and creating more liveable environments for improving human wellbeing.

\section{Introduction}

The land-energy-air nexus is central to achieving the United Nations (UN) Sustainable Development Goals (SDGs) by 2030 in and around urban areas ${ }^{1,2}$. With unprecedented urbanization rates, urban dwellers consume up to $60 \%$ of global resources ${ }^{2}$; resource use in surrounding rural areas has also increased rapidly over the recent decade ${ }^{3,4}$. Simultaneously, between 2010 and 2016, air quality deteriorated for more than half of the world's population, jeopardizing people's health, mainly in cities in Asia and Africa ${ }^{2}$. Such crises of natural resources and environmental quality have become major challenges in achieving SDGs worldwide ${ }^{5,6}$. Relevant indicators - land use efficiency (SDG 11.3.1), energy efficiency (SDG 7.3.1), and air quality (SDG 11.6.2) - have been established for tracking the sustainable development of cities and communities (SDG 11) ${ }^{1}$. The trends of these indicators are connected in several ways (Fig. 1 ), and can only be jointly assessed by using a spatially disaggregated nexus approach; a rapidly expanding new concept for investigating trade-offs and synergies across multiple SDG targets ${ }^{7}$. 


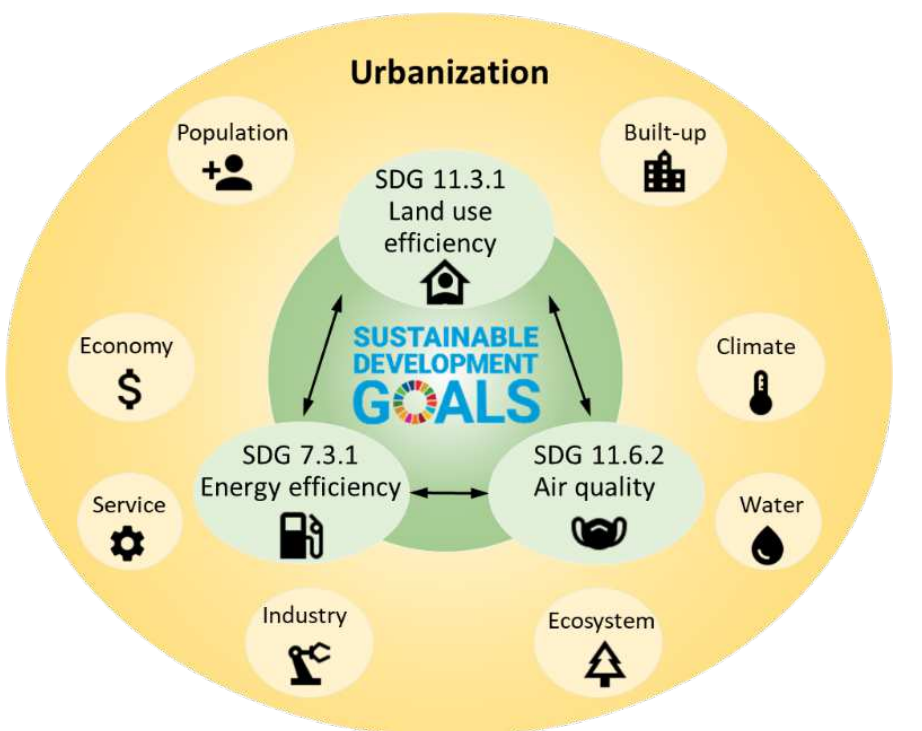

Fig. 1 Conceptual framework of the land-energy-air nexus in the context of urbanization.

Previous research highlights significant urban-rural differences in land use efficiency ${ }^{8}$, energy consumption ${ }^{9}$, efficiency ${ }^{10}$, and air quality ${ }^{11}$, which vary across regions in the Global North and South ${ }^{12}$. Synergies and trade-offs within the land-energy-air nexus have been mostly studied for urban ecosystems ${ }^{13}$, i.e. how population growth and built-up land expansion increase energy consumption and deteriorate air quality in urban areas of South Africa ${ }^{14}$. Declining sulfur dioxide emissions are largely due to a reduced energy intensity in Europe ${ }^{15}$, and urban air pollution could drive down energy intensity in China ${ }^{16}$. These studies demonstrate that context-specific strategies are needed for national SDG target setting ${ }^{12,17}$, but they remain regional and limited in scope. In particular, global urban-rural differences in the land-energy-air nexus remain largely unknown for SDG indicators, such as land use and energy efficiency. We argue that understanding the local land-energy-air nexus from a global perspective can support contextspecific solutions and win-win-win strategies for multiple SDG targets.

Recently, the UN called for a data revolution ${ }^{18}$, in particular for the integration of various Earth Observation (EO) data for the timely monitoring of SDG indicators and nexuses in high spatial detail ${ }^{7}$. EO-data are open, transparent and have the ability to underpin sustainability analysis in a consistent way across the world ${ }^{19}$. The EO-data allow movement beyond the standard evaluations of SDG performance that are available as national aggregates and with limited global comparability ${ }^{20,21}$. The EO-data are relevant at the level of cities or specific rural-urban gradients where sustainability actions are expected to make a difference. Recent high-resolution EO-data can help address the inequality in data availability for the Global South ${ }^{12,18}$. Integrating EO-data to explore the land-energy-air nexus will contribute to 'big nexus data'7 for guiding strategies to minimize the trade-offs between SDG targets. Additionally, turning timely EO-data into direct information for policy-makers is crucial for sustainable developments ${ }^{18}$. 
In this study, we perform an integrated analysis using multiple EO-data (Global Human Settlements, Nighttime Lights, and Near surface PM2.5) to monitor three SDGs: land use efficiency, energy efficiency, and air quality at the $1 \mathrm{~km}$ resolution worldwide, from 2000 to 2015. Synergy and trade-offs between the three SDG trends are explored using the nexus approach. SDG performances are further scored for comparing urban-rural gradients across continents. By doing so, we unravel the co-occurrences of land-energy-air nexus and provide high spatial detail that international policymakers can use to assess and achieve sustainability.

\section{Results}

\section{Global mapping of sustainability trends}

We reveal that, at the global scale, energy efficiency (SDG 7.3.1) performed better than land use efficiency (SDG 11.3.1) and air quality (SDG 11.6.2) between 2000 and 2015. In nearly $60 \%$ of the global inhabited grid cells, energy efficiency improved by using less primary energy to produce one unit of economic output (Fig. 2b). In contrast, land use efficiency only increased in $34 \%$ of the cells, with less built-up land consumption per capita (Fig. 2a). Improved air quality appeared in about $37 \%$ (Fig. 2c), while in nearly $57 \%$ of global inhabited grid cells, PM2.5 concentrations exceeded the WHO guideline level of $10 \mu \mathrm{g} / \mathrm{m}^{3}$ in 2015 (Supplementary Fig. 1d). These general trends are in line with the global SDG reports ${ }^{20}$, but our maps present detailed spatial information and allow for regional policy recommendations.

With relatively low land use efficiency in 2015 (Supplementary Fig. 1a) and enlarged built-up area per capita since 2000 (Supplementary Fig. 2a), the rural areas of Europe, Northeast US and South Africa need more policy attention to enhance sustainable urbanization (Target 11.3). According to the current status (Supplementary Fig. 1c) and changes of energy intensity (Fig. 2b; Supplementary Fig. 2c), the US and rural areas in the Global South need better energy policies to improve their relatively low energy efficiency (Target 7.3). With high PM2.5 concentration in 2015 (Supplementary Fig. 1d) and aggravated air pollution since 2000 (Fig. 2c; Supplementary Fig. 2d), Asian countries such as India and China should be targeted for extra efforts to improve air quality (Target 11.6 ).

\section{Complex patterns in urban-rural gradients}

Regarding land use efficiency, worldwide, we observe better performance in urban areas compared to rural areas between 2000 and 2015 (Fig. 2a; Supplementary Fig. 2a) as has previously been reported ${ }^{8}$, with the exception of some cities in North America (Supplementary Text 1). Specifically, land use efficiency in most city centers is stable or has increased, while it has decreased in most rural areas. Decreased rural land use efficiency means increased built-up areas occupied by each rural inhabitant; this can be caused by either population decline and/or 
excessive built-up expansion. In Northwest Europe, the main driver of decreasing land use efficiency can be attributed to the ageing population, which has led to reduced household size ${ }^{22}$. In Eastern China, decreasing rural land use efficiency is an effect of dispersed industrial land use patterns ${ }^{3}$, as well as inefficient residential land use caused by rapid built-up construction and rural population decline due to the migration to urban areas ${ }^{4,23}$. This regional variation shows that the SDG 11.3.1 strategies should depend on local context targeting for population revival or to compact built-up expansion patterns.

Regarding energy efficiency, measuring by primary energy consumption/GDP, urban-rural gradient patterns are opposite in the Global North and South (Fig. 2b; Supplementary Fig. 2c). In North US, Canada, and Europe, decreased energy efficiency mostly occurs in metropolitan city centers such as Toronto, Detroit, Los Angeles, Chicago, Paris, and Berlin. Such decreasing urban energy efficiency might be related to a changing sectoral structure and declining economies (Supplementary Text 1). Improved energy efficiency in North US, Europe, and Japan can be mainly attributed to actual decreased energy consumption (Supplementary Fig. 2b). In contrast, energy efficiency in South Asia and Africa increased particularly in urban centers but decreased in their surrounding exurbias (Fig. 2b). Examples include Johannesburg, New Delhi, and Beijing. Improved energy efficiency in China and India mainly results from increased GDP rates, since the energy consumption in most cells increased as well (Supplementary Fig. 2b). Decreased rural energy efficiency in the Global South might be due to the relocation of manufacturing from urban to rural ${ }^{11}$.

Concerning our third SDG, air quality, we did not find a clear urban-rural divide. Instead, our general observation is that air quality is strongly affected by geographical and climate conditions (Fig. 2c). Moderate urban-rural gradients are observed in certain Chinese cities. In 2015, air pollution was largely higher in urban centers than in the surrounding suburbs (Supplementary Fig. 1d), but since 2000, increased rates of PM2.5 concentrations in the suburbs have outweighed those in urban centers (e.g. Shenzhen and Chengdu) (Supplementary Fig. 2d). This could be due to environmentally unfriendly factories being moved from urban to rural areas to mitigate urban haze pollution ${ }^{11}$. Therefore, improving rural air quality is as important as mitigating urban air pollution for the currently most polluted continent: Asia. 


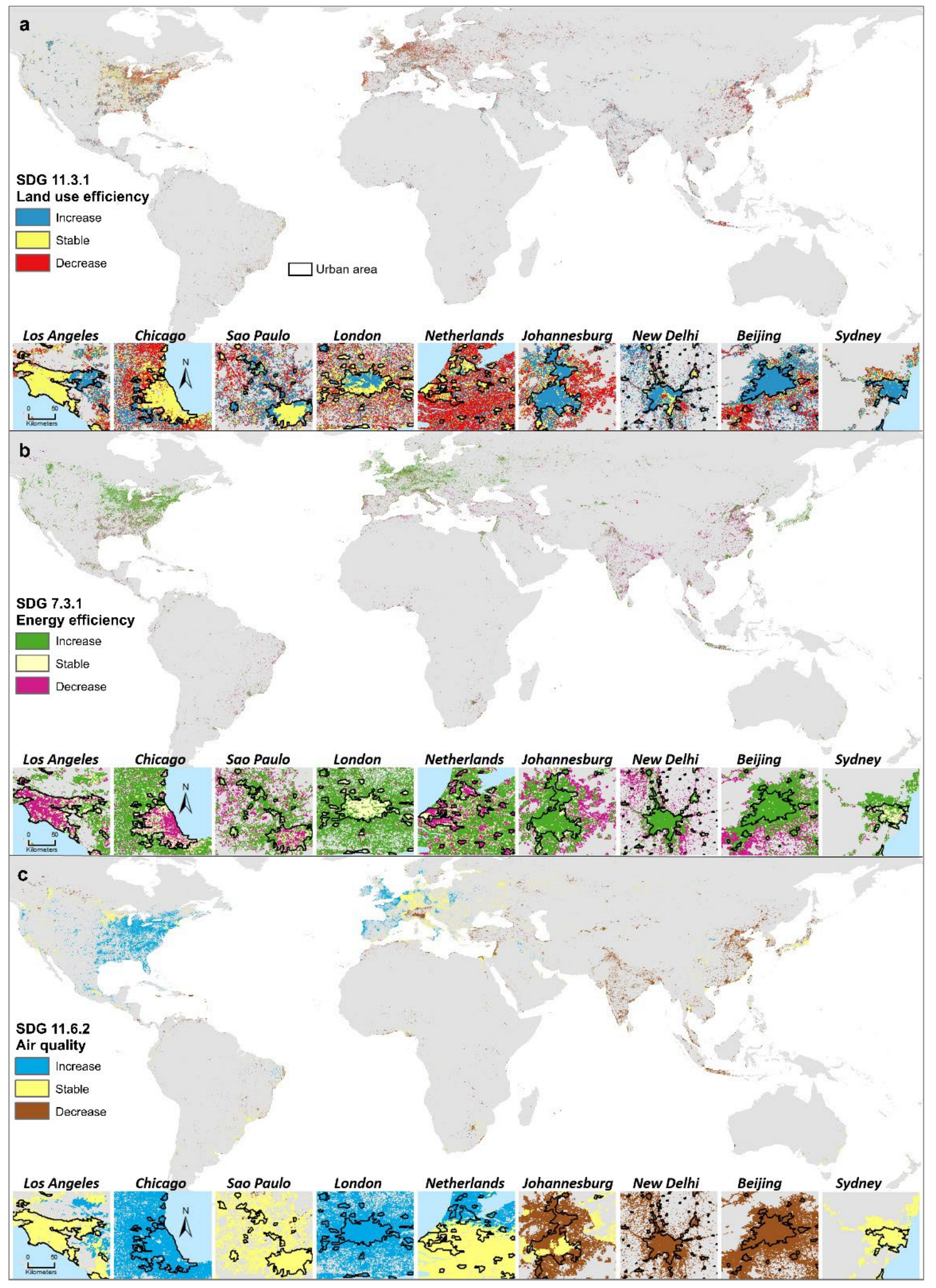

Fig. 2 Global SDG trends between 2000 and 2015 at $1 \mathrm{~km}$ resolution. a, Trend of land use efficiency, indicated by the change of built-up land per capita. 'Increase' of land use efficiency means the annual reduction rate of built-up land per capita is over 0.01 . b, Trend of energy efficiency, indicated by the change of energy intensity (primary energy consumption per 
128 GDP). 'Increase' of energy efficiency means the annual reduction rate of energy intensity is over 129 0.01. c, Trend of air quality, indicated by the change of annual mean PM2.5. 'Increase' of air 130 quality means the annual reduction rate of PM2.5 is over 0.01 . These grid cells cover all the 131 inhabited areas worldwide. Examples in the figures reflect the urban-rural gradient in typical 132 cities in the Global North and South.

\section{Different sustainability trade-offs in urban and rural areas}

134 We identified eight synergy/trade-off types for the land-energy-air nexus based on changes of 135 land use efficiency, energy efficiency, and air quality (Fig. 3a), including two fully synergy 136 types: win-win-win type (green areas) and lose-lose-lose type (red areas), as well as six tradeoff types. First, we found an urban-rural divide in the land-energy-air nexus. Most identified trade-offs in urban areas concern energy efficiency versus air quality (Fig. 3b), while trade-offs between land use efficiency and the other two SDGs are common in suburban and rural areas (Fig. 3c-d). Secondly, the Global North and South experience opposite directions in trade-offs between resource use (land use and energy) efficiency and air quality. In the Global North, in urban areas, especially in megacities (Fig. 3a-b), energy efficiency declined but air quality improved (orange and yellow areas), while in the Global South, energy efficiency improved, but air quality still declined (chocolate and plum areas).

Previous discussions on SDG trade-offs have mostly concerned resource use for social development and adverse environmental impacts; for example, how building infrastructure could negatively impact urban ecosystems ${ }^{13}$ and how using coal to improve energy access would accelerate climate change and air pollution ${ }^{24}$. Our study adds the spatial aspect of tradeoffs between resource use efficiency and air quality. For instance, our maps show that in Asian and African cities, air quality declined even when energy efficiency improved (Fig 3a-b). Since the positive relationship between changes of energy intensity and PM2.5 concentration is demonstrated by this study $(P<0.01)$ and previous research ${ }^{25}$, governments of countries in Asia and South Africa should not only keep improving primary energy efficiency, but also searching for other effective actions, such as improving the share of renewable energy ${ }^{26}$ (Supplementary

Fig. 3). Such trade-offs inspire local policymakers to rethink if the efforts undertaken are taking effect or just running on a treadmill 27. 


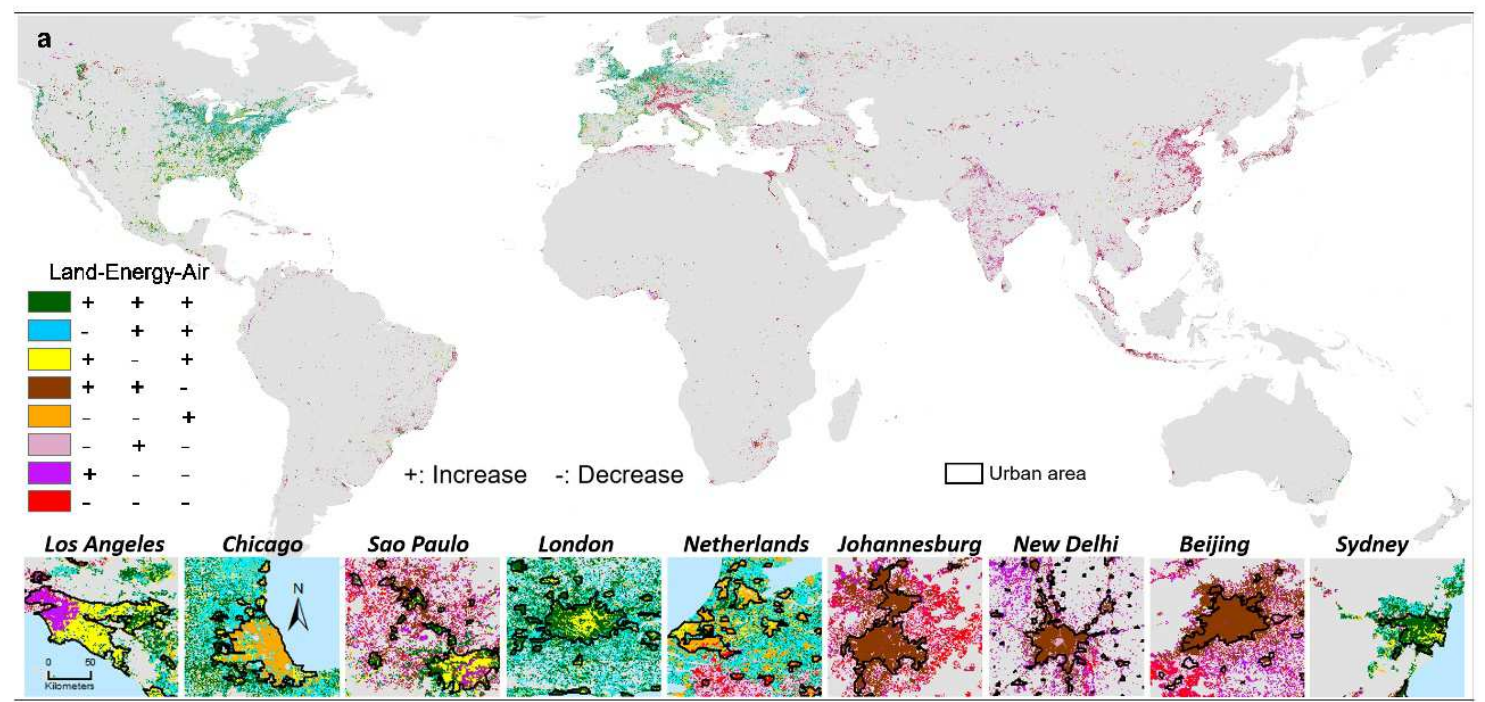

b. Urban areas

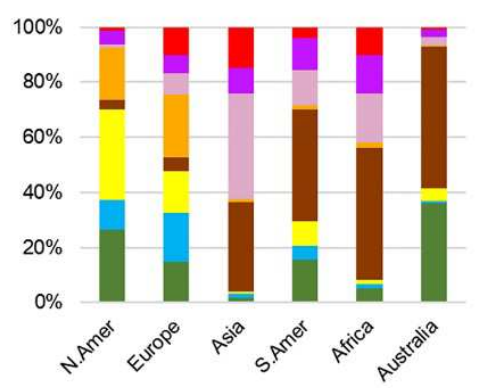

c. Suburban areas

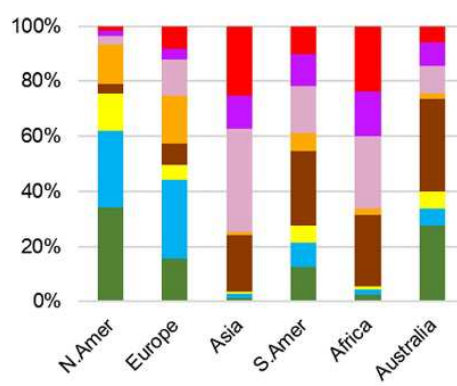

d. Rural areas

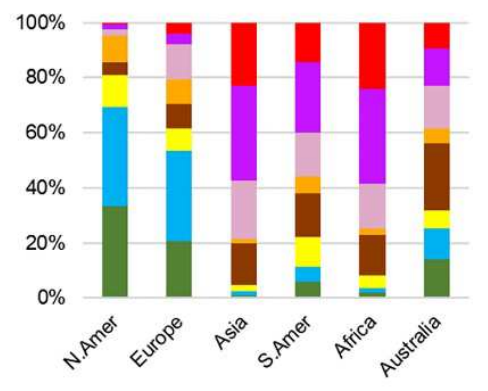

Fig. 3 Land-energy-air nexus between 2000 and 2015. a, Synergy/trade-off types, classified by the direction of changes in SDG targets. The + and - signs show whether the performance of SDG target is increased or decreased (+ means target increased as the indicator decreased). b-d, stacked column plots, showing the proportion of synergy/trade-off types in continents for urban, suburban, and rural areas, respectively.

\section{The least sustainable: rural areas in the Global South}

The Global South was less sustainable than the Global North during 2000-2015, according to the overall score of SDG change rates (Fig. 4a; Supplementary Fig. 4). This can be related to industrialization in developing countries ${ }^{28}$, as developed countries have increasingly shifted their focus toward improving environmental quality ${ }^{26,27}$. Such North-South differences are also revealed by a previous global study on urban socio-environmental sustainability in terms of social development, air quality, water, and energy ${ }^{12}$. Our analysis highlights even more dramatic North-South differences in suburban and rural areas compared to the small NorthSouth difference in urban areas (Fig. 4a; Supplementary Fig. 4). Furthermore, cities that we identified as more sustainable are also those that people find more livable (Supplementary Fig. $6)$. 
174 In addition to the urban-rural heterogeneity observed for individual SDG trends, the overall 175 scores of SDG trends show significant urban-suburban-rural differences $(P<0.05)$ (Fig. $4 a)$, and 176 urban-rural gradients in the Global North and South are opposite. In the Global North, urban areas are less sustainable than rural areas and have significantly higher rural SDG scores $(P<0.05)$. In contrast, urban areas are clearly more sustainable than suburban and rural areas in the South (Fig. 4a), and the lose-lose-lose type (red in Fig. 3b-d) makes up a larger proportion in rural areas than in urban areas. Thus, improving sustainability particularly in suburban and rural areas of the Global South is the key to reaching global land-energy-air targets.

With urban sustainability being high on national and international policy agendas ${ }^{12,29}$, it is important to note that, currently, urban residents consume more natural resources than rural residents (Supplementary Fig. 1b). At the same time, our results imply that sustainability issues in rural areas have become critical for the Global South, with decreased rural resource use efficiency since 2000 (Fig. 2a-b) and lower rural resource use efficiency compared to urban areas in 2015 (Supplementary Fig. 1a,c). Since rural areas occupy more land than urban centres, rural low-resource-use-efficient activities could lead to more unsustainable inhabited areas overall. Low land use efficiency in newly urbanized areas could replace significant surfaces of agricultural land and therefore has more adverse environmental impacts than for established

a

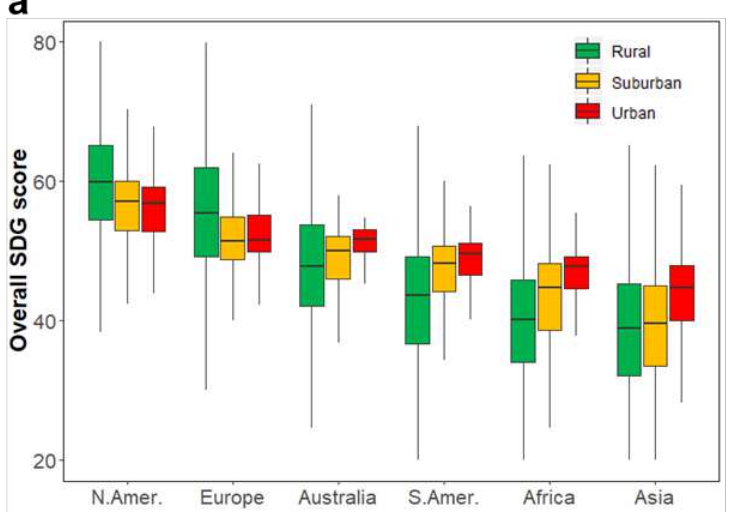

b

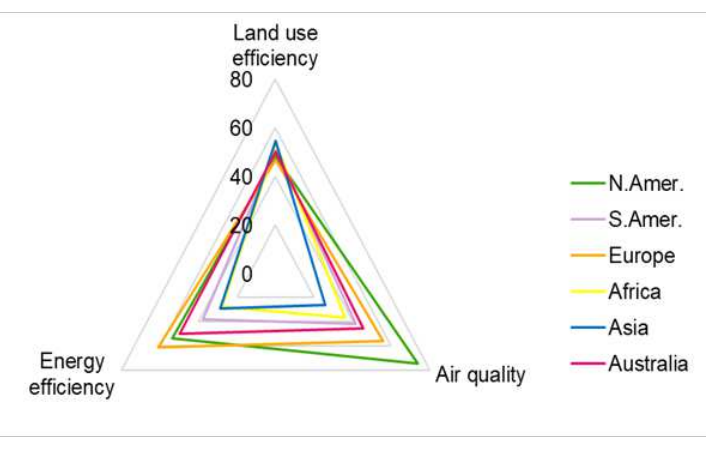


max normalized SDG changes multiplied by 100 . Differences between urban, suburban, and rural areas are statistically significant at $\mathrm{P}<0.05$ in each continent, using a t-test. $\mathbf{b}$, Radar plot of individual SDG scores, calculated by the min-max normalized SDG changes multiplied by 100. Higher score means more sustainable. The median value per continent was taken to reduce the influence of outliers.

\section{Discussion: better data and approaches for SDG monitoring}

Our $1 \mathrm{~km}$-gridded maps provide essential spatially detailed information on the land-energy-air nexus for understanding main patterns and trends, and for informing policymakers of effective local and regional actions. First, our data contribute to the SDG data revolution ${ }^{18}$. The global maps consistently cover every inhabited cell, which is beneficial for 'data-poor' regions and support their efforts towards the SDGs ${ }^{12,18}$. Second, previous global reports at national and subnational levels showed the general trends of SDGs, regardless of local variation within countries, urban/rural areas and even within cities ${ }^{20}$. Our maps reveal diverse urban and rural issues for the Global North and South, such as deteriorated air quality in the urban South, declined energy efficiency in the urban North and rural South, and decreased land use efficiency in the rural North (Fig. 2-3). National SDG strategies can be more effective when regional and local sustainability challenges are known, i.e. it is important to be aware of differences within megacities or small-sized cities (Fig. 2-3). Third, despite various land-energy-air trade-offs across regions, win-win-win regions exist (see parts of London and Sydney as green areas in Fig. 3a) and should be studied in more detail on why they are able to perform better than others. Local trade-offs reflected by our map (Fig. 3) can guide the context-specific strategies to transform all inhabited areas into win-win-win regions.

Potential improvements beyond the current SDG guidelines can be conducted for monitoring SDG indicators at a global scale. For SDG 11.3.1, the official calculation procedures are not easily applicable in population declining regions that exists in various parts of the world ${ }^{32}$. Our approach was adapted for such circumstances to include the change rate of built-up area per capita, which can indicate land use efficiency in any region. In addition, the rationale of SDG 11.3.1 is that cities require orderly urban expansion that makes the land use more efficient, yet the over-densification in urban land is not really considered. For SDG 7.3.1, the official definition of energy intensity is for the supply-side energy of economic activities but the suggested disaggregation methodology is for consumer-side energy ${ }^{33}$. In addition, SDGs mainly consider energy efficiency as energy per GDP, yet energy consumption per capita is also important for mitigating the energy crisis $^{34}$. For SDG 11.6.2, the data sources recommended in the guideline are ground-based observations limited to the regional scale ${ }^{35}$, regardless of the potential products from remote sensing field, which can provide increasingly fine-scale PM2.5 
concentration. Including more satellite-based products is important for more disaggregated monitoring of SDGs at a fine scale with large spatial and temporal coverage.

\section{Methods}

\section{Improved calculation of land use efficiency}

SDG 11.3 aims to enhance inclusive and sustainable urbanization and capacity for participatory, integrated, and sustainable human settlement planning and management in all countries by $2030^{20}$. To achieve this target, cities require an orderly, built-up expansion that makes the land use more efficient. SDG indicator 11.3 .1 is officially defined as the ratio of land consumption rate to population growth rate, referred to as land use efficiency (LUE) ${ }^{32}$. For the measurement, the United Nations Human Settlements Programme (UN-HABITAT) workshop suggests using the built-up area and population within the built-up land ${ }^{32}$. However, the official definition has a widely-noticed limitation: it is difficult to capture the dynamics of cities with negative or zero population growth ${ }^{36,37}$. To overcome this limitation, the Joint Research Centre (JRC) has developed the formulation of LUE to built-up area per capita ${ }^{36}$, and we adopted the calculation of annual change rate from the metadata of SDG 11.3.1:

Annual change rate of Built - up area per capita $=\ln \frac{\frac{\text { Built-up area }_{2015}}{\text { Population }_{2015}}}{\frac{\text { Built-uparea } 2000}{\text { Population } n_{2000}}} / 15$

The improved formulation of LUE expresses a more indicative concept that increased built-up area occupied by each person means decreased land use efficiency ${ }^{36}$. Negative change rates represent increased land use efficiency, while positive values indicate decreased land use efficiency. Logged change rates can obscure outliers, which are necessary for better visualization of the global gridded map.

The Global Human Settlement Layer (GHSL) is the official data source for monitoring SDG 11.3.132. In this study, the GHSL released in 2016 (GHS P2016) was used to calculate built-up area per capita in each $1 \mathrm{~km}$ grid cell. The multi-temporal built-up pixels (GHS-BUILT) describe the presence of built-up land at $38 \mathrm{~m}$ resolution for a long-term period (1975-2015), which were extracted from Landsat image archives using a Symbolic Machine Learning approach. More detail can be found in Pesaresi and Freire (2016) ${ }^{38}$. GHS-BUILT has been proven to be accurate and reliable for capturing global built-up changes, even in complex urban centers and low density peri-urban areas 39,40 . Assuming that built-up area and population are usually consistent in amount, Freire et al. (2015) disaggregated population censuses from Gridded Population of the World (GPW) into 250 m grids according to built-up information in the GHS-BUILT grids ${ }^{41}$. This finally resulted in data of population counts per $250 \mathrm{~m}$ grid (GHS-POP), disregarding administrative boundaries. 
273 National statistics of primary energy consumption in 2000 and 2015 were obtained from the U.S. Energy Information Administration (EIA) ${ }^{42}$. The statistics include coal, petroleum, natural gas, and renewable energy consisting of net nuclear, hydroelectric, and non-hydroelectric renewable electricity. The recommended data source by the UN for SDG 7.3.13 is the International Energy Agency (IEA) dataset, which only covers OECD countries ${ }^{43}$; comparatively, EIA provides free primary energy data for all countries in the world. We compared the primary energy of OECD countries from EIA and IEA, and found that the numbers are similar, which further proves that our data source from EIA is reliable. Although SDG 7.3.1 is for supply-side energy, downscaling consumer-side energy from national statistics to grid cells is feasible according to previous studies ${ }^{44,45}$.

Since energy consumption at the grid level is not available, spatial proxy data can be used to downscale the national statistics ${ }^{44,45}$. The most common proxy data is population distribution ${ }^{45}$, and recently, the nighttime light dataset has been regarded as a proxy to downscale energy consumption ${ }^{44}$. Previous research often first split the national energy consumption into urban energy and rural energy, and then downscaled this to grid cells separately. However, the national ratio of urban energy consumption is not suitable for all cities because it can cause underestimation for certain mega-cities ${ }^{44}$. Since population and nighttime lights have been widely used to divide urban and rural areas ${ }^{46}$, we combined them as the spatial proxy to downscale national statistical energy consumption. The GHS-POP provides population counts per $250 \mathrm{~m}$ grid cell, and a harmonized global nighttime light dataset 1992-2018 provides consistent digital number (DN) values from 0 to 63 at $1 \mathrm{~km}$ resolution for the year 2000 and $2015^{47}$. Noise caused by cloud, solar illumination, aurora, and temporal lights have been removed in this nighttime light dataset ${ }^{47}$. We further eliminated night-light emission in nonpopulated regions to reduce the 'blooming' effect ${ }^{48}$. The remaining bright pixels are relevant to human activities, which can indicate the distribution of energy consumption. As we were aware that most pixels in urban centers have similar highest DN values (63), demographic information (GHS-POP) provide an independent complement to night-light brightness within urban centers.

To downscale the national primary energy consumption, we first built linear regression models between energy consumption and two proxy indicators (population and nighttime light) at the country level for the year 2000 and 2015 separately (equation 2). Standardized regression coefficients $\left(\beta_{1}, \beta_{2}\right)$ in the models were used as weights of two proxy indicators. We adopted a weighted linear downscale approach ${ }^{9,49}$, since strong linear relationships between energy consumption and population/nighttime lights have been proven in previous studies ${ }^{49,50}$ and this study (Supplementary Fig. 7). Based on equation (3), we generated primary energy consumption maps at the $1 \mathrm{~km}$ grid level for 2000 and 2015. 
Energy $_{\text {grid }-i}=$ Energy $_{\text {country }} \times\left(\beta_{1} \times \frac{\text { Light }_{\text {grid }-i}}{\text { Light }_{\text {country }}}+\beta_{2} \times \frac{\text { Population }_{\text {grid }-i}}{\text { Population }_{\text {country }}}\right)$

Our estimates of gridded energy consumption were validated by the statistical energy consumption regionally, both at the state level in the United States ${ }^{51}$ and at the neighborhood level in the Netherlands ${ }^{52}$ for the year 2015. The validation results show that our estimated gridded maps are generally reliable and in line with statistical data at the state/neighborhood level (Supplementary Fig. 8a-b). We also compared our gridded map with the existing global gridded anthropogenic heat flux dataset in $2015^{45}$ and observed deviations from the one-to-one line (Supplementary Fig. 8c). Such deviations are possibly caused by different statistical data sources and methods that the existing dataset ${ }^{45}$ only used population as spatial proxy while we added nighttime light data to reduce the uncertainty of downscaling.

\section{Energy efficiency}

SDG 7.3 aims to double the global rate of improvement in energy efficiency by 2030, which requires tracking of SDG indicator 7.3.1: energy intensity across the world. Energy intensity is measured as the primary energy per GDP. A global gridded GDP dataset is available for the year 2000 and 2015, based on sub-national and national GDP per capita, and gridded population $\left(\right.$ GHS-POP) ${ }^{53}$. We used the obtained gridded energy consumption and gridded GDP to calculate the trend of SDG 7.3.1 between 2000 and 2015:

Annual change rate of Energy intensity $=\ln \frac{\frac{\text { Energy consumption }_{2015}}{G P_{2015}}}{\frac{\text { Energy consumption } 2000}{G P_{2000}}} / 15$

Negative change rates indicate improved energy efficiency (less energy is used to produce one unit of economic output), while positive numbers indicate decreased energy efficiency.

\section{Air quality represented by PM2.5}

The Global Annual PM2.5 Grids provide annual concentrations (micrograms per cubic meter) of ground-level fine particulate matter (PM2.5) at $1 \mathrm{~km}$ resolution from 1998 to $2016^{54}$. The PM2.5 concentration was estimated by aerosol optical depth from multiple satellite products (MISR, MODIS Dark Target, MODIS and SeaWiFS Deep Blue, and MODIS MAIAC), with dust and seasalt removed. Global ground-based measurements were used to predict and adjust for the residual PM2.5 bias per grid cell in the initial satellite-derived values by Geographically Weighted Regression (GWR). The resultant PM2.5 estimates were highly consistent $\left(R^{2}=0.81\right)$ with out-of-sample cross-validated ground-based measurements ${ }^{54}$. With the relatively high accuracy for inhabited land, this product is widely used to analyze temporal dynamics of air quality in small to large cities internationally ${ }^{55}$. To monitor SDG 11.6.2 - annual mean levels of 
fine particulate matter (e.g. PM2.5 and PM10) in cities - we used this product to produce the global $1 \mathrm{~km}$ map of SDG 11.6 .2 trend:

Annual change rate of $P M 2.5=\ln \frac{P M 2.5 \text { concentration }_{2015}}{P M 2.5 \text { concentration }_{2000}} / 15$

Negative change rates indicate improved air quality (less PM2.5 concentration), while positive numbers represent declined air quality.

\section{Mapping land-energy-air nexus}

Nexus approaches are highly recommended for analysis of trade-offs among SDG indicators $5,7,56$. Statistical models and diverse indicators were used for quantitative nexus analysis; indicators that can combine nexus variables into a single number are common in nexus research. Mapping out the score to qualify interactions between SDG targets is suggested as a simple way to rate local trade-offs for practical policy making ${ }^{24}$. Based on this theory, we combined the directions of multiple SDG trends into archetypes of land-energy-air nexus for each $1 \mathrm{~km}$ grid cell. Two fully synergy types with consistent change directions of land-energyair targets, and six trade-off types with inconsistent change directions among land-energy-air nexus were detected in this study.

\section{Scoring the performance of land-energy-air SDGs}

Min-max normalized scores are typically used for comparing performance of SDG targets and indicators across regions ${ }^{6}$. Here, we also produced individual SDG scores based on the change rate of each SDG indicator (equation 6), ranging from 0 to 100 . Although the change rate was logged, many outliers with extreme values still remain in the obtained change rate map, which can influence the min-max normalization. Thus, we removed statistical outliers for each change rate map before the min-max normalization. Normalized change rates needed to be inverted to get the final SDG score because increasing SDG indicator signifies decreasing SDG target. In doing so, higher scores represent better performance towards the SDG target (e.g. energy efficiency) as the corresponding SDG indicator (e.g. energy intensity) decreases. The overall SDG score was calculated by the average of three individual SDG scores, representing the overall performance of land-energy-air nexus. Finally, we revealed the continental differences in individual SDG performance and urban-suburban-rural gradient in overall SDG performance (Fig. 4).

$S D G$ score $_{\text {grid }-i}=\left(1-\frac{\text { Change rate }_{\text {grid }-i}-\text { minimum global change rate }}{\text { maximum global change rate-minimum global change rate }}\right) \times 100$

\section{Uncertainties and limitations}

Although the GHSL dataset is the best option for monitoring land use efficiency, there are several limitations in GHS-BUILT and GHS-POP. For GHS-BUILT, the identification of built-up 
land in rural areas is less accurate than that in urban areas ${ }^{39,40}$. Built-up land in rural areas is scattered and rare, making the previous global land cover products (e.g. CCI-LC and MOD500) almost entirely neglected small settlements within cropland ${ }^{39}$. Until 2016, the GHSL captured built-up land (manmade roofs) in rural areas at $38 \mathrm{~m}$ resolution with temporal consistent (1975-1990-2000-2015), but there still exist potential risks of overestimating settlement areas due to $30 \mathrm{~m}$ Landsat images ${ }^{57}$, such as for the rural Tuscany region ${ }^{39}$. GUF has higher resolution than GHSL for built-up land, but its usefulness is limited by inadequate temporal coverage ${ }^{58,59}$. Multi-temporal and refined global maps for the built-up land are needed for improving the accuracy of monitoring land use efficiency in rural areas. Moreover, the GHS-POP was mainly disaggregated from census data and distributed proportionally over build-up density. Yet, functional land use of buildings and their height were not considered in the process of population disaggregation ${ }^{60}$. By including this information on buildings across the world, more feasible gridded population and land use efficiency can be produced.

Our country-level energy data reflects the consumer-side, which makes it possible to disaggregate by nighttime lights and population. However, the SDG indicator 7.3.1 suggested by the UN, reflects the supply-side energy. For rural areas in Asia, consumer-side energy might be lower than supply-side energy, since a portion of secondary energy consumed by urban residents is produced in rural areas using the primary energy (e.g. the coal used by power stations to generate electricity $)^{44}$. Although we combined two spatial proxy indicators nighttime lights and population - some uncertainties still exist in the disaggregation process from top to bottom. For instance, the distribution of energy consumption within urban centers has been based mainly on the gridded population because the nighttime lights in urban grid cells tend to be equal to the maximum digital number (63). This implies that each urban resident consumes the same amount of energy in any given city. Given the uncertainties at the local scale, reporting supply-side energy data from the bottom, such as collecting from factories would be necessary to reduce the dependency on country-level statistics and to further improve the guideline for SDG 7.3.1.

The nexus concept is still evolving and it is challenging to univocally adopt a default approach and standardize indicators ${ }^{56}$, particularly for the quantification at a global scale. Most previous research explored the general trade-offs between SDG targets across regions, and the global trade-offs on land-energy-air mainly remains at the theoretical level ${ }^{13,61}$. We provided a new perspective on mapping trade-offs and synergies among SDG indicators globally. Various local trade-offs and synergies we detected could provide accurate information for policy makers. Since we were limited by the temporal coverage of public global data, we only explored interactions based on the directions of SDG trends between two epochs. Future mapping studies can use long-time-series datasets with multiple epochs to score the interactions between SDG indicators for each grid cell ${ }^{24}$. 
1. United Nations. Global indicator framework for the Sustainable Development Goals and targets of the 2030 Agenda for Sustainable Development. Work Stat. Comm. Pertain. to 2030 Agenda Sustain. Dev. (2020).

2. United Nations. The sustainable development goals report 2019. United Nations Publ. issued by Dep. Econ. Soc. Aff. 64 (2019).

3. Jiang, G., Ma, W., Dingyang, Z., Qinglei, Z. \& Ruijuan, Z. Agglomeration or dispersion? Industrial land-use pattern and its impacts in rural areas from China's township and village enterprises perspective. J. Clean. Prod. (2017). doi:10.1016/j.jclepro.2017.04.152

4. Wang, H., Wang, L., Su, F. \& Tao, R. Rural residential properties in China: Land use patterns, efficiency and prospects for reform. Habitat Int. (2012). doi: $10.1016 /$ j.habitatint.2011.06.004

5. Bleischwitz, R. et al. Resource nexus perspectives towards the United Nations Sustainable Development Goals. Nat. Sustain. 1, 737-743 (2018).

6. Zeng, Y. et al. Environmental destruction not avoided with the Sustainable Development Goals. Nat. Sustain. 3, 795-798 (2020).

7. Liu, J. et al. Nexus approaches to global sustainable development. Nat. Sustain. 1, 466476 (2018).

8. Schiavina, M. et al. Multi-scale estimation of land use efficiency (SDG 11.3.1) across 25 Years Using Global Open and Free Data. Sustain. 11, 1-25 (2019).

9. van Vuuren, D. P., Lucas, P. L. \& Hilderink, H. Downscaling drivers of global environmental change: Enabling use of global SRES scenarios at the national and grid levels. Glob. Environ. Chang. 17, 114-130 (2007).

10. Tan, L. M., Arbabi, H., Densley Tingley, D., Brockway, P. E. \& Mayfield, M. Mapping resource effectiveness across urban systems. npj Urban Sustain. 1, 1-14 (2021).

11. Han, L., Zhou, W. \& Li, W. Increasing impact of urban fine particles (PM2.5) on areas surrounding Chinese cities. Sci. Rep. (2015). doi:10.1038/srep12467

12. Nagendra, H., Bai, X., Brondizio, E. S. \& Lwasa, S. The urban south and the predicament of global sustainability. Nat. Sustain. 1, 341-349 (2018).

13. Maes, M. J. A., Jones, K. E., Toledano, M. B. \& Milligan, B. Mapping synergies and tradeoffs between urban ecosystems and the sustainable development goals. Environ. Sci. 
Policy 93, 181-188 (2019).

14. Shikwambana, L. \& Tsoeleng, L. T. Impacts of population growth and land use on air quality. A case study of Tshwane, Rustenburg and Emalahleni, South Africa. South African Geogr. J. (2020). doi:10.1080/03736245.2019.1670234

15. Rafaj, P., Amann, M., Siri, J. \& Wuester, H. Changes in European greenhouse gas and air pollutant emissions 1960-2010: Decomposition of determining factors. Clim. Change (2014). doi:10.1007/s10584-013-0826-0

16. Hou, J., Wang, J., Chen, J. \& He, F. Does urban haze pollution inversely drive down the energy intensity? A perspective from environmental regulation. Sustain. Dev. 28, 343351 (2020).

17. Blanchard, J. L. et al. Linked sustainability challenges and trade-offs among fisheries, aquaculture and agriculture. Nat. Ecol. Evol. (2017). doi:10.1038/s41559-017-0258-8

18. United Nations. A World that Counts: Mobilising the Data Revolution for Sustainable Development. IEAG (2020). doi:10.7551/mitpress/12439.003.0018

19. Cochran, F., Daniel, J., Jackson, L. \& Neale, A. Earth observation-based ecosystem services indicators for national and subnational reporting of the sustainable development goals. Remote Sens. Environ. 244, 111796 (2020).

20. Council, S. \& Council, S. SDG Progress Report 2020. United Nations (2020).

21. The World Bank and International Energy Agency. Global Tracking Framework 2017. in Global Tracking Framework: Progress toward Sustainable energy (2017).

22. Franklin, R. S. \& van Leeuwen, E. S. For Whom the Bells Toll: Alonso and a Regional Science of Decline. Int. Reg. Sci. Rev. 41, 134-151 (2018).

23. Yu, X. J. \& Ng, C. N. Spatial and temporal dynamics of urban sprawl along two urbanrural transects: A case study of Guangzhou, China. Landsc. Urban Plan. 79, 96-109 (2007).

24. Nilsson, M., Griggs, D. \& Visbeck, M. Policy: Map the interactions between Sustainable Development Goals. Nature 534, 320-322 (2016).

25. Chen, J., Zhou, C., Wang, S. \& Li, S. Impacts of energy consumption structure, energy intensity, economic growth, urbanization on PM2.5 concentrations in countries globally. Appl. Energy 230, 94-105 (2018).

26. Akram, R., Chen, F., Khalid, F., Ye, Z. \& Majeed, M. T. Heterogeneous effects of energy efficiency and renewable energy on carbon emissions: Evidence from developing 
countries. J. Clean. Prod. (2020). doi:10.1016/j.jclepro.2019.119122

27. Reflections on Sustainability. Nat. Sustain. 4, 921 (2021).

28. Sadorsky, P. Do urbanization and industrialization affect energy intensity in developing countries? Energy Econ. (2013). doi:10.1016/j.eneco.2013.01.009

29. Zhou, W. et al. Beyond city expansion: multi-scale environmental impacts of urban megaregion formation in China. Natl. Sci. Rev. (2021). doi:10.1093/nsr/nwab107

30. Zhou, W., Pickett, S. \& McPhearson, T. Conceptual Frameworks Facilitate Integration for Transdisciplinary Urban Science. npj Urban Sustain. 1-11 doi:10.1038/s42949-02000011-9

31. Liu, Y. Exploring the relationship between urbanization and energy consumption in China using ARDL (autoregressive distributed lag) and FDM (factor decomposition model). Energy 34, 1846-1854 (2009).

32. UN-Habitat. Metadata on SDGs Indicator 11.3.1. 1-12 (2018).

33. United Nations. Metadata on SDGs Indicator 7.3.1. (2021). Available at: https://unstats.un.org/sdgs/metadata/files/Metadata-07-03-01.pdf.

34. Sikder, S. K., Nagarajan, M., Kar, S. \& Koetter, T. A geospatial approach of downscaling urban energy consumption density in mega-city Dhaka, Bangladesh. Urban Clim. 26, 1030 (2018).

35. United Nations. Metadata on SDGs Indicator 11.6.2. (2021). Available at: https://unstats.un.org/sdgs/metadata/files/Metadata-11-06-02.pdf.

36. Paresi, M., Melchiorri, M., Siragusa, A. \& Kemper, T. Atlas of the Human Planet. Mapping Human Presence on Earth with the Global Human Settlement Layer. (2017). doi: $10.2788 / 889483$

37. Melchiorri, M., Pesaresi, M., Florczyk, A., Corbane, C. \& Kemper, T. Principles and Applications of the Global Human Settlement Layer as Baseline for the Land Use Efficiency Indicator-SDG 11.3.1. ISPRS Int. J. Geo-Information 8, 96 (2019).

38. Pesaresi, M. \& Freire, S. GHS-SMOD R2016A - GHS settlement grid, following the REGIO model 2014 in application to GHSL Landsat and CIESIN GPW v4-multitemporal (19751990-2000-2015). Eur. Comm. Jt. Res. Cent. (2016).

39. Klotz, M., Kemper, T., Geiß, C., Esch, T. \& Taubenböck, H. How good is the map? A multiscale cross-comparison framework for global settlement layers: Evidence from Central Europe. Remote Sens. Environ. (2016). doi:10.1016/j.rse.2016.03.001 
40. Leyk, S., Uhl, J. H., Balk, D. \& Jones, B. Assessing the accuracy of multi-temporal builtup land layers across rural-urban trajectories in the United States. Remote Sens. Environ. (2018). doi:10.1016/j.rse.2017.08.035

41. Freire, S., Kemper, T., Pesaresi, M., Florczyk, A. \& Syrris, V. Combining GHSL and GPW to improve global population mapping. in International Geoscience and Remote Sensing Symposium (IGARSS) (2015). doi:10.1109/IGARSS.2015.7326329

42. U.S. Energy Information Administration (EIA). International Energy Statistics: Total Primary Energy Consumption. Available at:

https://www.eia.gov/international/data/world/total-energy/.

43. IEA. World Energy Statistics and Balances. IEA World Energy Statistics and Balances (database) (2018).

44. Yang, W. et al. Data Descriptor: A new global anthropogenic heat estimation based on high-resolution nighttime light data. Sci. Data 4, 1-11 (2017).

45. Jin, K. et al. A new global gridded anthropogenic heat flux dataset with high spatial resolution and long-term time series. Sci. Data 6, 1-14 (2019).

46. Zhou, Y. et al. A global map of urban extent from nightlights. Environ. Res. Lett. 10, 2000-2010 (2015).

47. Li, X., Zhou, Y., Zhao, M. \& Zhao, X. A harmonized global nighttime light dataset 19922018. Sci. Data 7, 1-9 (2020).

48. Wang, L. et al. Mapping population density in China between 1990 and 2010 using remote sensing. Remote Sens. Environ. 210, 269-281 (2018).

49. Dong, Y., Varquez, A. C. G. \& Kanda, M. Global anthropogenic heat flux database with high spatial resolution. Atmos. Environ. 150, 276-294 (2017).

50. Xiao, H. et al. Spatio-temporal simulation of energy consumption in China's provinces based on satellite night-time light data. Appl. Energy 231, 1070-1078 (2018).

51. U.S. Energy Information Administration (EIA). State Energy Data System. (2021). Available at: https://www.eia.gov/state/seds/seds-data-complete.php?sid=US.

52. Netherlands, S. Wijk- en Buurtkaart 2017. (2018).

53. Kummu, M., Taka, M. \& Guillaume, J. H. A. Gridded global datasets for Gross Domestic Product and Human Development Index over 1990-2015. Sci. Data 5, 1-15 (2018).

54. Van Donkelaar, A. et al. Global Estimates of Fine Particulate Matter using a Combined Geophysical-Statistical Method with Information from Satellites, Models, and Monitors. 
Environ. Sci. Technol. 50, 3762-3772 (2016).

55. Liang, L. \& Gong, P. Urban and air pollution: a multi-city study of long-term effects of urban landscape patterns on air quality trends. Sci. Rep. (2020). doi:10.1038/s41598020-74524-9

56. Næss, J. S., Cavalett, O. \& Cherubini, F. The land-energy-water nexus of global bioenergy potentials from abandoned cropland. Nat. Sustain. 4, 525-536 (2021).

57. Sabo, F. et al. Comparison of built-up area maps produced within the global human settlement framework. Trans. GIS 22, 1406-1436 (2018).

58. Esch, T. et al. Breaking new ground in mapping human settlements from space - The Global Urban Footprint. ISPRS J. Photogramm. Remote Sens. (2017). doi:10.1016/j.isprsjprs.2017.10.012

59. Liu, C. et al. Automatic extraction of built-up area from ZY3 multi-view satellite imagery: Analysis of 45 global cities. Remote Sens. Environ. (2019). doi:10.1016/j.rse.2019.03.033

60. Freire, S., Macmanus, K., Pesaresi, M. \& Doxsey-Whitfield, E. Development of new open and free multi-temporal global population grids at $250 \mathrm{~m}$ resolution Validation of remote sensing derived emergency mapping maps View project Megacities View project. (2016).

61. Fuso Nerini, F. et al. Mapping synergies and trade-offs between energy and the Sustainable Development Goals. Nat. Energy 3, 10-15 (2018). 


\section{Supplementary Files}

This is a list of supplementary files associated with this preprint. Click to download.

- 4.Supplementary.docx 